\title{
A COMPARATIVE STUDY ON INTRAOCULAR PRESSURE CHANGES ON INSERTION OF ENDOTRACHEAL TUBE, AMBU AURAGAIN AND I-GEL IN PAEDIATRIC PATIENTS IN NON-OCULAR SURGERIES
}

\author{
Priyanka Dwivedi', Shailendra Upadhyay2 ${ }^{2}$ Satish Kumar ${ }^{3}$, Narendra Deo ${ }^{4}$, Shahbaz Ahmad ${ }^{5}$, Santosh Sharma ${ }^{6}$, Raka Rani $^{7}$, \\ Aashish Agarwal ${ }^{8}$

\begin{abstract}
${ }^{1}$ Assistant Professor, Department of Anaesthesia and Critical Care, BRD Medical College, Gorakhpur.
${ }^{2}$ Resident, Department of Anaesthesia and Critical Care, BRD Medical College, Gorakhpur.

${ }^{3}$ Professor, Department of Anaesthesia and Critical Care, BRD Medical College, Gorakhpur.

${ }^{4}$ Assistant Professor, Department of Anaesthesia and Critical Care, BRD Medical College, Gorakhpur.

${ }^{5}$ Associate Professor, Department of Anaesthesia and Critical Care, BRD Medical College, Gorakhpur.

${ }^{6}$ Assistant Professor, Department of Anaesthesia and Critical Care, BRD Medical College, Gorakhpur.

${ }^{7}$ Professor, Department of Anaesthesia and Critical Care, BRD Medical College, Gorakhpur.

${ }^{8}$ Senior Resident, Department of Anaesthesia and Critical Care, BRD Medical College, Gorakhpur.
\end{abstract}

ABSTRACT

\section{BACKGROUND}

Newer supraglottic devices provide better perilaryngeal seal and cause lesser sympathetic stimulation and IOP changes, so they can be used as an alternative to conventional laryngoscopy and intubation.

The aim of the study is to compare the changes in Intraocular Pressure (IOP) during and after insertion of endotracheal tube, Ambu AuraGain and I-gel in paediatric patients in non-ocular surgeries.

\section{MATERIALS AND METHODS}

A total of 45 paediatric patients, aged 1-12 years, of either sex, ASA grade I-II, posted for elective non-ocular surgeries under general anaesthesia were randomly divided into three groups of 15 patients each, in whom airways were secured by one of the devices. IOP changes of both eyes were measured at various pre-defined time intervals and mean IOPs were calculated and compared between the groups. Data was analysed using SPSS 23 and presented as Mean \pm SD. Test applied: one-way ANOVA. Value of $\mathrm{p}<0.05$ was considered statistically significant while $\mathrm{p}<0.001$ was considered highly significant.

\section{RESULTS}

Both AMBU AuraGain and I-gel insertion caused lesser percentage increase in IOPs (10.69\% and I-gel 3.73\% respectively) unlike endotracheal intubation which caused highly significant $42.26 \%$ increase in IOP ( $p$ value $<0.001$ ). After initial rise, Post-insertion IOPs were equal to or below their baseline pre-insertion values with AMBU AuraGain and I-gel unlike endotracheal tube where IOPs exceeded pre-insertion values at all times of observations. Though IOP changes were statistically non-significant ( $p$ value $>0.05$ ) between AMBU AuraGain and I-gel, I-gel showed better stability over AMBU AuraGain clinically. Both devices also provide stable IOPs prior to their removal unlike endotracheal extubation.

\section{CONCLUSION}

Ambu AuraGain and I-gel are better alternatives to endotracheal tubes for securing airway in paediatric patients under general anaesthesia as far as stability of IOP is concerned.

\section{KEYWORDS}

Intraocular Pressure, AMBU AuraGain, I-gel, Paediatric Surgeries, Non-ocular Surgeries.

HOW TO CITE THIS ARTICLE: Dwivedi P, Upadhyay S, Kumar S, et al. A comparative study on intraocular pressure changes on insertion of endotracheal tube, Ambu AuraGain and I-gel in paediatric patients in non-ocular surgeries. J. Evolution Med. Dent. Sci. 2017;6(75):5376-5381, DOI: 10.14260/Jemds/2017/1166

\begin{tabular}{|c|}
\hline $\begin{array}{l}\text { BACKGROUND } \\
\text { The goals of general anaesthe } \\
\text { a smooth endotracheal in } \\
\text { pressure (IOP), avoidance of } \\
\text { motionless field, and smooth } \\
\text { accomplished with inhaled } \\
\text { anaesthesia, or intravenously }\end{array}$ \\
\hline $\begin{array}{l}\text { Financial or Other, Competing Inter } \\
\text { Submission 17-07-2017, Peer Revie } \\
\text { Acceptance 11-09-2017, Published } \\
\text { Corresponding Author: } \\
\text { Dr. Narendra Deo, } \\
\text { Department of Anaesthesia and Crit } \\
\text { BRD Medical College, } \\
\text { Gorakhpur-273013. } \\
\text { E-mail: drpriyad1111@gmail.com } \\
\text { DOI: } 10.14260 / \text { jemds/2017/1166 } \\
\begin{array}{l}\text { c) }(\text { ) } \\
\text { (i) }\end{array}\end{array}$ \\
\hline
\end{tabular}
or without muscle relaxants.[1] For the conduit of anaesthetic gases and securing airway, various airway devices are used, out of which laryngoscopy-guided endotracheal intubation is the gold standard and routinely done procedure but at a cost of markedly deleterious effects on cardiovascular functions (tachycardia, hypertension), raised Intraocular Pressure (IOP) and Intracranial tension owing to sympathoadrenal stimulation. $[2,3,4,5]$

Supraglottic airway devices have brought revolutionary change in airway management. In cases of elective and difficult airway management, SADs are increasingly preferred due to their confirmed efficacy and safety[6] and nowadays they are used for maintenance of airway in paediatric patients too with lesser complications and failure rates compared to conventional laryngoscopy and intubation. ${ }^{[7,8]}$

Among the supraglottic devices, various changes have been enforced to improve the perilaryngeal seal and reduce 
risk of aspiration. Also, sympathetic stimulation has been found lesser in second generation SADs. Newer SADs also offer easy and quick conduit for endotracheal intubation if and when required. I-gel is an effective and safe alternative to endotracheal intubation for use in children. [7] Recently AMBU Aura Gain has also been launched with aforesaid safety measures.

The effects of these devices on IOP changes and superiority of one device over another are unclear because of inadequate number of comparative studies on these issues. This clinical study was done to compare the intraocular pressure changes on insertion of endotracheal tube, AMBU Aura Gain and I-gel in paediatric patients in non-ocular surgeries.

\section{MATERIALS AND METHODS}

After institutional ethical committee approval and written informed consent from patient's guardians, a randomised controlled trial study was conducted on 45 patients aged 112 years, of either sex, ASA grade I-II, posted for elective nonocular surgeries under general anaesthesia.

Based on total paediatric surgeries conducted in the institute in a year, total 45 patients, with $80 \%$ statistical power, $95 \%$ confidence interval, $5 \%$ significance level/allowable error using online $\mathrm{G}$ power software were selected for the study. Sample size was calculated by calculating the effect size. Effect size was calculated by using changes in mean IOP at 5 minutes after device insertion and prior to device removal in all the three groups with using Gpower software. Hence, it was decided to include 15 patients in each group. So finally, there were 45 patients (15 in each three group).

Patients with anticipated difficult airway, restricted mouth opening, cervical spine disease, history of regurgitation, cardiovascular or pulmonary disease, glaucoma, history of previous ocular surgery, patients receiving any drug affecting IOP and more than 3 attempts of the device insertion in securing airway were excluded from the study.

Patients were randomly divided into 3 groups of 15 patients each; using computer generated random sequence, for securing airway by one of the airway devices.

Group T: Endotracheal intubation, Group A: Ambu AuraGain, Group IG: I-Gel.

Pre-anaesthetic check-up was done for each patient with detailed history, complete general, physical and airway examination, routine laboratory investigations and recording of relevant demographic data. A pre-operative ophthalmic assessment of patient was also done to examine anterior chamber of eyes by ophthalmologist and measure IOP using Schiotz tonometer (The Diagnostic Company: Riester, Germany). Prior to IOP measurement, Schiotz tonometer was kept in formalin chamber and its footplate was disinfected with Isopropyl alcohol. Patients' guardians were explained about the advantages and the possible disadvantages of the SADs. Children were advised Nil per oral according to latest guidelines.

In the preoperative area, baseline parameters (PR, SBP, DBP, MAP, and SPO2) were taken and after applying EMLA cream for at least 30 minutes, intravenous lines secured and patients were taken into the operating room. Multipara monitors with standard monitoring were attached to the patient. After preoxygenation with $100 \% \mathrm{O}_{2}$ for 3 minutes all patients were premedicated with midazolam $0.05 \mathrm{mg} / \mathrm{kg} \mathrm{IV}$, glycopyrrolate $0.01 \mathrm{mg} / \mathrm{kg}$ IV and fentanyl $1-1.5 \mathrm{mcg} / \mathrm{kg}$ IV. Induction of anaesthesia was done with inj. Thiopentone titrated to loss of eyelash reflex. Neuromuscular blockade was done with Inj. vecuronium bromide $0.1 \mathrm{mg} / \mathrm{kg}$ after ensuring face mask ventilation adequacy. After selecting appropriate-sized endotracheal tube/SAD, according to the manufacturer's recommendation based on body weights of the patients, water based lubricant gel was applied on the exterior surface of SAD and the endotracheal tube before insertion. SAD insertion and endotracheal intubation was done in recommended position and technique in the respective groups. All SAD insertions were performed by the anaesthesiologists who were experts in paediatric airway/anaesthesia and SAD. After insertion of device, the cuff was inflated for endotracheal tube and the AMBU AuraGain, at the recommended volume and the airway devices were connected to paediatric circuit. Hearing bilateral equal lung sounds, the existence of bilateral equal chest wall expansion and confirmation of end-tidal carbon dioxide $\left(\mathrm{ETCO}_{2}\right)$ trace in capnography were accepted as adequate and effective ventilation.

In each patient, an ophthalmologist measured IOP in both eyes previously prepared with lubricant eye drops, just before insertion of the airway device and subsequently at 1, 3 and $5 \mathrm{~min}$. after insertion of the device. All IOP measurements were done under strict aseptic conditions. By evaluating the pressures of both eyes, the mean IOP was calculated. Intraocular Pressure between 10.5-20.5 mmHg was accepted as normal IOP. The surgery was allowed only after noting study parameters.

Anaesthesia was maintained with Isoflurane $(0.6-1 \%$ concentration) and $\mathrm{N}_{2} \mathrm{O} \& \mathrm{O}_{2}$ in $(50 ; 50)$ with top-up doses of Inj. Vecuronium $0.01 \mathrm{mg} / \mathrm{kg}$ for maintenance of neuromuscular blockade. Isoflurane was stopped towards the end of surgery. IOP was again measured before giving neuromuscular reversal agents and an antibiotic eye drop was applied to both eyes. The residual neuromuscular blockade was reversed by neostigmine $0.05 \mathrm{mg} / \mathrm{kg}$ and glycopyrrolate $0.02 \mathrm{mg} / \mathrm{kg}$ IV. Airway device was removed after the patient was fully conscious, with eyes open and following verbal command.

Data was analysed using SPSS (Statistic Package for Social Sciences, Chicago, USA) version 23. Continuous variables and descriptive statistics were presented as mean \pm standard deviation and categorical variables were presented as the number of observations and percentage (\%). Significance of difference in means between the groups was evaluated using t-test and one-way ANOVA. Tukey's and Sidak's multiple comparison tests were applied for intra \& intergroup multiple comparisons of data. For all statistical analysis, the value of $\mathrm{p}<0.05$ was considered to be statistically significant while $\mathrm{p}<0.001$ was considered highly statistically significant.

\section{RESULTS}

All three groups were comparable in their mean ages, mean weights, ASA grades, mean surgery durations and mean 
anaesthesia durations (table 1). We observed Mean intraocular pressure (mean IOP) and percentage changes in mean IOP prior to and at $1 \mathrm{~min}$., $3 \mathrm{~min}$., $5 \mathrm{~min}$. after device insertion and prior to device removal in all the three groups (Figure $1 \& 2$ ). In group T, baseline mean IOP was $11.43 \pm$ $1.556 \mathrm{mmHg}$ which raised $42.26 \%(16.26 \pm 1.906 \mathrm{mmHg})$ after 1 min. of intubation ( $\mathrm{p}<0.0001$ ) and remained higher at $3 \mathrm{~min}$. (13.90 $\pm 1.485 \mathrm{mmHg}$ ) and $5 \mathrm{~min}$. (12.05 \pm 1.292 $\mathrm{mmHg}$ ) when compared with baseline which was statistically significant. Prior to extubation, mean IOP again raised $37.97 \%$ from baseline $(15.77 \pm 1.712 \mathrm{mmHg})$ which was highly significant (Table 2).

In Ambu AuraGain group, baseline mean IOP was $11.69 \pm$ $1.204 \mathrm{mmHg}$ which increased $10.69 \%$ (12.94 $\pm 0.963 \mathrm{mmHg}$ ) after $1 \mathrm{~min}$. of device insertion and gradually decreased at 3 min. $(10.87 \pm 1.004 \mathrm{mmHg})$ and $5 \mathrm{~min} .(9.49 \pm 0.923 \mathrm{mmHg})$ to levels lower than baseline IOPs which were statistically highly significant. Prior to device removal, mean IOP raised slightly $(10.85 \pm 0.949 \mathrm{mmHg})$ though values were still lower than baseline IOP (p 0.0022) (Table 2).

In I-gel group, mean IOP did not increase much (3.73\%) after device insertion at $1 \mathrm{~min}$. (11.97 $\pm 1.179 \mathrm{mmHg})$ when compared with baseline IOP value (11.54 $\pm 1.469 \mathrm{mmHg})(\mathrm{p}$ $0.0199)$ and gradually decreased at $3 \mathrm{~min}$. (10.50 \pm 1.337 $\mathrm{mmHg})$ and $5 \mathrm{~min}$. (9.34 $\pm 0.998 \mathrm{mmHg})$ after device insertion $(\mathrm{p}<0.0001)$. Prior to device removal, mean IOP raised $(9.88 \pm 0.836 \mathrm{mmHg})$ but remained lower than baseline mean IOP $(\mathrm{p}<0.0001)$ (Table 2$)$.

We compared Mean IOP changes between group T \& A at various time intervals (table 3 ). Pre-Induction and Preinsertion values were comparable in both the groups ( $\mathrm{p}$ value $>0.9999$ ). The changes in mean Intraocular Pressure values were statistically highly significant at post-insertion $1 \mathrm{~min}$. (p value 0.0001 ), $3 \mathrm{~min}$. ( $\mathrm{p}$ value $<0.0001$ ), $5 \mathrm{~min}$. ( $\mathrm{p}$ value $<0.0001$ ) and prior to device removal ( $p$ value $<0.0001$ ) between the two groups. It can be seen from the Table 2 that mean IOP in group $\mathrm{T}$ showed an abrupt increase following intubation and started settling down towards the end of 5 minutes, but it always remained higher than its pre-insertion values after intubation (figure 1). In contrast, mean IOP in group A increased slightly after Ambu AuraGain insertion (10.69\% vs. $42.26 \%$ ) (Figure 2) but started settling down 2-3 minutes after insertion and always remained lower than its pre-insertion values. (Table 3). Even prior to device removal in group A, lesser IOP changes were observed in comparison to group $\mathrm{T}(\mathrm{p}<0.0001)$.

Table 4 shows inter-group comparison of mean IOP changes between group T \& IG at various time intervals. Both Pre-Induction and Pre-insertion values were comparable in both the groups. The changes in mean Intraocular Pressure values were statistically highly significant at post-insertion 1 min. (p value <0.0001), 3 min. (p value 0.0001), 5 min. (p value $<0.0003$ ) and prior to device removal ( $p$ value $<0.0001)$. Mean IOP in I-Gel group increased marginally after I-gel insertion (3.73\%) which started settling down 2-3 minutes after its insertion and always remained lower than the pre-insertion values at all times of observations (figure 1) in comparison to group T. Even prior to I-gel removal, IOP was associated with lesser changes and mean IOP remained below pre-insertion value in comparison to group $\mathrm{T}$.

Table 5 compares mean IOP changes between Group A \& IG at various time intervals. Both the groups had comparable Pre-Induction and Pre-insertion values. One minute after device insertion, both groups showed marginal rise and mean IOP in group A increased by $10.69 \%$ compared to $3.73 \%$ increase above Pre-Insertion IOP in group IG (figure 2). At post-insertion $3 \mathrm{~min}$, mean IOP decreased in both the groups, but the decrease was more in group IG (9.01\%) when compared to group A $(7.01 \%)$ from their respective preinsertion IOP values. Similarly, at 5 minutes after device insertions, mean IOP in group A decreased by $18.82 \%$ in comparison to group IG where IOP decreased more i.e. $19.06 \%$ from pre-insertion value. Prior to device removal, mean IOPs showed increase in both the groups but IOP was still $7.19 \%$ lesser than pre-insertion value in group A in comparison to group IG where mean IOP was $14.38 \%$ lesser than pre-insertion value. The mean IOP values were statistically not significant at any time of observations ( $p$ value $>0.05$ ) when the two groups were compared. It can be observed here that both Ambu AuraGain and I-gel are associated with statistically insignificant rise in mean IOP 1 minute after device insertion in their respective groups ( $p$ 0.1269 ) but clinically, rise in mean IOP in group IG is comparatively lesser than group A.

\begin{tabular}{|c|c|c|c|c|}
\hline & Group T & Group A & Group IG & P value (One way ANOVA) \\
\hline Mean Age (years) & $6.43 \pm 3.064$ & $6.57 \pm 3.064$ & $5.87 \pm 3.518$ & 0.82 \\
\hline Sex (M:F) & $11: 4$ & $10: 5$ & $10: 5$ & \\
\hline Mean Weight (Kg) & $22.47 \pm 8.518$ & $22.27 \pm 8.902$ & $20.20 \pm 9.025$ & 0.7396 \\
\hline ASA I/II & $15 / 0$ & $15 / 0$ & $15 / 0$ & \\
\hline Mean Surgery duration (min.) & $41.13 \pm 19.478$ & $46.60 \pm 23.485$ & $40.80 \pm 22.460$ & 0.7190 \\
\hline Mean Anaesthesia duration (min.) & $56.73 \pm 19.466$ & $61.27 \pm 24.120$ & $56.20 \pm 22.409$ & 0.7889 \\
\hline \multicolumn{5}{|l|}{ Types of surgery } \\
\hline Lower Abdomen/pelvic, n (\%) & $8(53.33)$ & $10(63.67)$ & $12(80)$ & \\
\hline Lower Limb, n (\%) & $3(20)$ & $1(6.66)$ & $1(6.67)$ & \\
\hline $\begin{array}{c}\text { Others (post-burn contracture, } \\
\text { tongue-tie, fibroadenoma breast, etc.), } \\
\mathrm{n}(\%)\end{array}$ & $4(26.67)$ & $4(26.67)$ & $2(13.33)$ & \\
\hline \multicolumn{5}{|c|}{ Table 1} \\
\hline
\end{tabular}




\begin{tabular}{|c|c|c|c|c|c|c|c|c|c|}
\hline \multicolumn{4}{|c|}{ Group T } & \multicolumn{3}{|c|}{ Group A } & \multicolumn{3}{|c|}{ Group IG } \\
\hline Time interval & $\begin{array}{l}\text { Mean IOP } \\
\text { (mmHg) }\end{array}$ & $\begin{array}{c}\% \\
\text { Change } \\
\end{array}$ & $p$ value & $\begin{array}{l}\text { Mean IOP } \\
\text { (mmHg) }\end{array}$ & $\begin{array}{c}\% \\
\text { Change }\end{array}$ & p value & $\begin{array}{l}\text { Mean IOP } \\
\text { (mmHg) }\end{array}$ & \begin{tabular}{|c|}
$\%$ \\
Change \\
\end{tabular} & $p$ value \\
\hline Pre-induction* & $13.49 \pm 1.856$ & & & $13.69 \pm 1.441$ & & & $13.55 \pm 1.773$ & & \\
\hline $\begin{array}{c}\text { Pre-insertion } \\
\text { (Baseline) }\end{array}$ & $11.43 \pm 1.556$ & $-18.20 \downarrow$ & $<0.0001$ & $11.69 \pm 1.204$ & $-17.12 \downarrow$ & $<0.0001$ & $11.54 \pm 1.469$ & $-17.42 \downarrow$ & $<0.0001$ \\
\hline $\begin{array}{l}\text { Post-Insertion } 1 \\
\text { min. (T1)* }\end{array}$ & $16.26 \pm 1.906$ & $42.26 \uparrow$ & $<0.0001$ & $12.94 \pm 0.963$ & $10.69 \uparrow$ & $<0.0001$ & $11.97 \pm 1.179$ & $3.73 \uparrow$ & 0.0199 \\
\hline $\begin{array}{c}\begin{array}{c}\text { Post-Insertion } 3 \\
\text { min. (T3)* }\end{array} \\
\end{array}$ & $13.90 \pm 1.485$ & $21.61 \uparrow$ & $<0.0001$ & $10.87 \pm 1.004$ & $-7.01 \downarrow$ & $<0.0001$ & $10.50 \pm 1.337$ & $-9.01 \downarrow$ & $<0.0001$ \\
\hline $\begin{array}{c}\text { Post-Insertion } 5 \\
\text { min. (T5)* }\end{array}$ & $12.05 \pm 1.292$ & $5.42 \uparrow$ & 0.1381 & $9.49 \pm 0.923$ & $-18.82 \downarrow$ & $<0.0001$ & $9.34 \pm 0.998$ & $-19.06 \downarrow$ & $<0.0001$ \\
\hline $\begin{array}{c}\text { Prior to Removal } \\
\text { (TR)* }\end{array}$ & $15.77 \pm 1.712$ & $37.97 \uparrow$ & $<0.0001$ & $10.85 \pm 0.949$ & $-7.19 \downarrow$ & 0.0022 & $9.88 \pm 0.836$ & $-14.38 \downarrow$ & $<0.0001$ \\
\hline
\end{tabular}

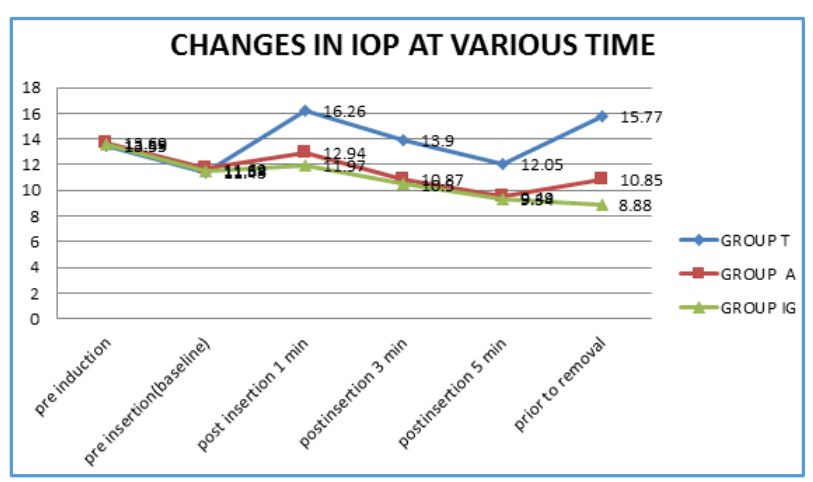

Figure 1

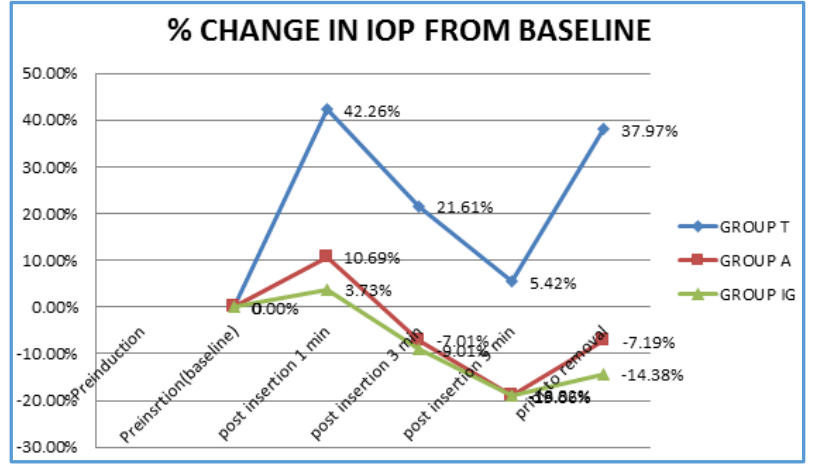

Figure 2

\begin{tabular}{|c|c|c|c|c|c|c|}
\hline \multirow{2}{*}{ Time interval } & \multicolumn{2}{|c|}{ Group T } & \multicolumn{2}{|c|}{ Group A } & \multirow{2}{*}{ t Value } & \multirow{2}{*}{ p value } \\
\hline & IOP (mmHg) & \% Change & IOP (mmHg) & \% Change & & \\
\hline Pre-induction* & $13.49 \pm 1.856$ & & $13.69 \pm 1.441$ & & 0.3364 & $>0.9999$ \\
\hline Pre-insertion (Baseline) & $11.43 \pm 1.556$ & $-18.20 \downarrow$ & $11.69 \pm 1.204$ & $-17.12 \downarrow$ & 0.5747 & 0.9230 \\
\hline Post-Insertion 1 min. (T1)* & $16.26 \pm 1.906$ & $42.26 \uparrow$ & $12.94 \pm 0.963$ & $10.69 \uparrow$ & 6.873 & 0.0001 \\
\hline Post-Insertion 3 min. (T3)* & $13.90 \pm 1.485$ & $21.61 \uparrow$ & $10.87 \pm 1.004$ & $-7.01 \downarrow$ & 7.652 & $<0.0001$ \\
\hline Post-Insertion 5 min. (T5)* & $12.05 \pm 1.292$ & $5.42 \uparrow$ & $9.49 \pm 0.923$ & $-18.82 \downarrow$ & 7.712 & $<0.0001$ \\
\hline Prior to Removal (TR)* & $15.77 \pm 1.712$ & $37.97 \uparrow$ & $10.85 \pm 0.949$ & $-7.19 \downarrow$ & 9.916 & $<0.0001$ \\
\hline
\end{tabular}

\begin{tabular}{|c|c|c|c|c|c|c|}
\hline \multirow{2}{*}{ Time interval } & \multicolumn{2}{|c|}{ Group T } & \multicolumn{2}{|c|}{ Group A } & \multirow{2}{*}{ t Value } & \multirow{2}{*}{ p value } \\
\hline & IOP (mmHg) & \% Change & IOP (mmHg) & \% Change & & \\
\hline Pre-induction* & $13.49 \pm 1.856$ & & $13.55 \pm 1.773$ & & 0.1076 & $>0.9999$ \\
\hline Pre-insertion (Baseline) & $11.43 \pm 1.556$ & $-18.20 \downarrow$ & $11.54 \pm 1.469$ & $-17.42 \downarrow$ & 0.2119 & 0.9955 \\
\hline Post-Insertion $1 \min (\mathrm{T} 1)^{*}$ & $16.26 \pm 1.906$ & $42.26 \uparrow$ & $11.97 \pm 1.179$ & $3.73 \uparrow$ & 8.106 & $<0.0001$ \\
\hline Post-Insertion $3 \mathrm{~min} .(\mathrm{T} 3)^{*}$ & $13.90 \pm 1.485$ & $21.61 \uparrow$ & $10.50 \pm 1.337$ & $-9.01 \downarrow$ & 6.885 & 0.0001 \\
\hline Post-Insertion 5 min. (T5)* & $12.05 \pm 1.292$ & $5.42 \uparrow$ & $9.34 \pm 0.998$ & $-19.06 \downarrow$ & 6.340 & 0.0003 \\
\hline Prior to Removal (TR)* & $15.77 \pm 1.712$ & $37.97 \uparrow$ & $9.88 \pm 0.836$ & $-14.38 \downarrow$ & 11.10 & $<0.0001$ \\
\hline
\end{tabular}

\begin{tabular}{|c|c|c|c|c|c|c|}
\hline \multirow{2}{*}{ Time interval } & \multicolumn{2}{|c|}{ Group T } & \multicolumn{2}{|c|}{ Group A } & \multirow{2}{*}{ t Value } & \multirow{2}{*}{ p value } \\
\cline { 2 - 6 } & IOP (mmHg) & \% Change & IOP (mmHg) & \% Change & & \\
\hline Pre-induction* & $13.69 \pm 1.441$ & & $13.55 \pm 1.773$ & & 0.2638 & $>0.9999$ \\
\hline Pre-insertion (Baseline) & $11.69 \pm 1.204$ & $-17.12 \downarrow$ & $11.54 \pm 1.469$ & $-17.42 \downarrow$ & 0.3415 & 0.9820 \\
\hline Post-Insertion 1 min. (T1)* & $12.94 \pm 0.963$ & $10.69 \uparrow$ & $11.97 \pm 1.179$ & $3.73 \uparrow$ & 3.121 & 0.1269 \\
\hline Post-Insertion 3 min. (T3)* & $10.87 \pm 1.004$ & $-7.01 \downarrow$ & $10.50 \pm 1.337$ & $-9.01 \downarrow$ & 1.116 & 0.9975 \\
\hline Post-Insertion 5 min. (T5)* & $9.49 \pm 0.923$ & $-18.82 \downarrow$ & $9.34 \pm 0.998$ & $-19.06 \downarrow$ & 0.4279 & $>0.9999$ \\
\hline Prior to Removal (TR)* & $10.85 \pm 0.949$ & $-7.19 \downarrow$ & $9.88 \pm 0.836$ & $-14.38 \downarrow$ & 3.170 & 0.1159 \\
\hline
\end{tabular}




\section{DISCUSSION}

Maintenance of safe airway with minimal complications has always been the utmost priority of the anaesthesiologist in general anaesthesia, and endotracheal intubation following direct laryngoscopy is the gold standard for this purpose. However, it is associated with markedly deleterious effects on cardiovascular function, intraocular pressure (IOP) and intracranial tension owing to sympathoadrenal stimulation. The stress response in form of raised IOP is associated not only with endotracheal intubation but also with Extubation.[2,9] Supraglottic airway devices offer many advantages over laryngoscopy and intubation with rapid access to airway, better haemodynamic stability and as conduit for ETT insertion.

In this study, we have used three different devices to maintain airway (ETT, I-Gel, and Ambu AuraGain), and observed as well as compared mean IOP at various times. It can be observed from the Table 2 and Figure 1 that in group $\mathrm{T}$ mean IOP values and the percentage changes were always higher than group A and group IG values. Even prior to removal of device, IOP could not raise to a level higher than baseline IOP values in I-gel and Ambu AuraGain group. This comparative stability in IOP in Group A and IG can be attributed to lesser sympathoadrenal stimulation caused by Ambu AuraGain and I-gel, like other SADs which cause less stimulation of pharyngeal and laryngeal structures in comparison to endotracheal tube. Our findings are similar to the previously conducted studies which compared the effect of ETT and LMA insertion on Intraocular Pressure and reported significant increase in IOP following endotracheal intubation in comparison to LMA insertion and emphasised that LMAs are effective substitutes of ETTs for securing airway when raised IOP is undesirable.[10,11,12,13]

It is a well-established fact that intraocular pressure rises after laryngoscopy and endotracheal intubation and same was observed in our study.[11] But insertion of supraglottic devices also causes some increases in IOP, though newer generation devices are said to cause lesser changes. Mean IOP changes following Ambu AuraGain and I-gel insertion in our study (10.69\% and $3.73 \%$ respectively) are lesser than IOP changes following Classic laryngeal Mask Airway insertion $(26.59 \%)$ as reported in a study[10] while no change in I-gel group has been observed in another study comparing I-gel, LMA and ETT.[14] So it can be concluded that both Ambu AuraGain and I-gel provides more stable IOP when compared to classic Laryngeal Mask Airway.

Ambu AuraGain (Ambu, Ballerup, Denmark) is a newer second-generation SAD with preformed anatomical shape, thin and soft inflatable cuff, an incorporated gastric channel and capability of working as a conduit for tracheal intubation. In recent years, various studies have been done on device performance and insertion parameters for this device,[15,16,17] but no study has been reported so far comparing the effect of insertion or removal of Ambu AuraGain on IOP.

Mean IOPs kept on decreasing in both the groups at different time intervals of observations after device insertions, but in group IG, mean IOPs were always lesser than Group A at all-time intervals and greater decrease in IOPs seen. This minimal change and stability of IOP with I-gel in comparison to Ambu AuraGain can be attributed to lesser sympathoadrenal stimulation of laryngopharyngeal structures by I-gel as it is non-cuffed and more anatomical in structure in comparison to Ambu AuraGain, which is a cuffed airway device and inflation of cuff always causes some, though small, compression of laryngopharyngeal structures and minimal sympathoadrenal stimulation.[14,16]

Limitations of our study include smaller sample size, nonophthalmic surgeries, Schiotz tonometer use and higher cost of Ambu AuraGain and I-gel in comparison to endotracheal tube. Larger study population with different age-groups and surgery durations are required to establish reliability of the results of the study. Study was not conducted in ophthalmic surgeries because it was not possible to interrupt the surgery and take IOP measurement frequently and once the affected eye is operated it is bandaged with sterile dressings. So, measurement of IOP is not possible in this condition.

Though both Ambu AuraGain and I-gel provide better IOP stability in comparison to endotracheal tube, they are not cost-effective. Schiotz tonometer is the commonly used device for measurement of IOP indirectly by indentation tonometry.[18] Readings may be less reliable because of variations in sclera rigidity among different patients. Also repeated measurements may displace aqueous humour, producing lower IOP readings. Use of more sensitive tonometers could have given more accurate estimation of IOP changes. While most of ocular and extraocular surgeries in adults are easily done under regional anaesthesia, anxious and non-cooperative paediatric patients usually require general anaesthesia for their surgeries, so we selected paediatric patients as our study group.

\section{CONCLUSION}

To sum up, it can be argued that both Ambu AuraGain and Igel provide better IOP stability during their insertion and removal when compared to endotracheal tube. This study recommends use of Ambu AuraGain and I-gel as airway devices in paediatric patients when significant changes in IOP are anticipated though more studies are needed to recommend these devices for routine usage.

\section{REFERENCES}

[1] Feldman MA. Miller's Anaesthsia. $8^{\text {th }}$ edn. Philadelphia: Elsevier's 2015:2516-18.

[2] Bishop MJ, Bedford RF, Kil HK. Physiologic and pathophysiologic responses to intubation. In: Benumof JL. edr. Airway management principles and practice. $1^{\text {st }}$ edn. Philadelphia, Mosby: Saunders 1996:102-17.

[3] Lamb K, James MF, Janicki PK. The laryngeal mask airway for intraocular surgery: effects on intraocular pressure and stress responses. $\mathrm{Br} \mathrm{J}$ Anaesth 1992;69(2):143-7.

[4] Kilickan L, Baykara N, Gurkan Y, et al. The effect on intraocular pressure of endotracheal intubation or laryngeal mask use during TIVA without the use of muscle relaxants. Acta Anaesthesiol Scand 1999;43(3):343-6.

[5] Keller C, Brimacombe J. Mucosal pressure and oropharyngeal leak pressure with the ProSeal verses the classic laryngeal mask airway in anaesthetized paralysed patients. Br J Anaesth 2000:85(2):262-6. 
[6] Braude N, Clements EA, Hodges UM, et al. The pressor response and laryngeal mask insertion. A comparison with tracheal intubation. Anaesthesia 1989;44(7):551-4.

[7] Beylacq L, Bordes M, Semjen F, et al. The I-gel, a single use supraglottic airway device with a non-inflatable cuff and an esophageal vent: an observational study in children. Acta Anaesthesiol Scand 2009;53(3):376-9.

[8] Ramesh S, Jayanthi R. Supraglottic airway devices in children. Indian Journal of Anaesthesia 2011;55(5): 476-82.

[9] Madan R, Tamilselvan P, Sadhasivam S, et al. Intraocular pressure and hemodynamic changes after tracheal intubation and extubation: a comparative study in glaucomatous and non-glaucomatous children. Anaesthesia 2000;55(4):380-4.

[10] Bukhari SA, Naqash I, Zargar J, et al. Pressor responses and intraocular pressure changes following insertion of laryngeal mask airway: comparison with tracheal tube insertion. Indian J Anaesth 2003;47(6):473-5.

[11] Ziyaeifard M, Azarfarin R, Massoumi G. A comparison of intraocular pressure and hemodynamic responses to insertion of laryngeal mask airway or endotracheal tube using anesthesia with propofol and remifentanil in cataract surgery. J Res Med Sci 2012;17(6):503-7.

[12] Pandya MJ, Agarwal G. Comparative study of intraocular pressure changes with laryngeal mask airway and endotracheal tube. National Journal of Community Medicine 2012;3(2):279-82.
[13] Rabbani MW, Haider SA, Fayyaz MA. Comparing the effect of LMA insertion and ETT intubation to induce general anaesthesia on IOP. P J M H S 2014;8(3): 673-6.

[14] Ismail SA, Bisher NA, Kandil HW, et al. Intraocular pressure and haemodynamic responses to insertion of the I-gel, laryngeal mask airway or endotracheal tube. European Journal of Anaesthesiology 2011;28(6): 443-8.

[15] Lopez AM, Sala-Blanch X, Valero R, et al. Cross-over assessment of the Ambu AuraGain, LMA supreme new cuff and Intersurgical I-gel in fresh cadavers. Open Journal of Anesthesiology 2014;(4):332-9.

[16] Peker G, Takmaz SA, Baltacı B, et al. Comparison of four different supraglottic airway devices in terms of efficacy, intra-ocular pressure and hemodynamic parameters in children undergoing ophthalmic surgery. Turk J Anaesth Reanim 2015;43(5):304-12.

[17] Jagannathan N, Hajduk J, Sohn L, et al. A randomised comparison of the Ambu AuraGain and the LMA supreme in infants and children. Anaesthesia 2016;71(2):205-12.

[18] Cunningham AJ, Barry P. Intraocular pressure-physiology and implications for anaesthetic management. Can Anaesth Soc J 1986;33(2):195-208. 